Conclusion This study adds substantially to the available efficacy data on celecoxib. It expands the data globally on the efficacy of celecoxib to various settings that closely follow local clinical practice. Celecoxib demonstrated similar efficacy to the most commonly prescribed regimen of diclofenac in the treatment of OA.

Sponsored by Pharmacia Corporation and Pfizer Inc.

\section{SAT0094 CELECOXIB DOES NOT INCREASE THE RISK OF CARDIAC FAILURE, OEDEMA, OR HYPERTENSION COMPARED TO NSAIDS: RESULTS FROM SUCCESS 1, A DOUBLE BLIND, RANDOMISED TRIAL IN 13,274 OA PATIENTS}

${ }^{1} \mathrm{~A}$ Whelton, ${ }^{2} \mathrm{G}$ Singh, ${ }^{3} \mathrm{~W}$ White, ${ }^{4} \mathrm{~J}$ Fort, ${ }^{4} \mathrm{~A}$ Bello. ${ }^{1}$ Universal Clinical Research Center, And, Johns Hopkins Medical School, Hunt Valley; ${ }^{2}$ School of Medicine, Stanford University, Palo Alto; ${ }^{3}$ Health Center, University of Connecticut, Farmington; ${ }^{4} \mathrm{Global}$ Medical Affairs, Pharmacia, Peapack, USA

\subsection{6/annrheumdis-2001.469}

Background COX-2 specific inhibitors have been shown to significantly reduce the risk of gastrointestinal complications compared to conventional NSAIDs, while providing equivalent efficacy. However, some recent studies have raised concerns about the cardiovascular and renal safety profile of COX-2 inhibitors. In a previous study of 7,968 patients in North America, celecoxib at supratherapeutic doses $(800 \mathrm{mg} / \mathrm{d})$ was shown not to increase the risk of hypertension, congestive heart failure, or renal adverse events compared to therapeutic doses of ibuprofen and diclofenac.

Objectives To compare the risk of congestive heart failure, oedema, and hypertension in OA patients treated with celecoxib at 200 or $400 \mathrm{mg}$ per day compared to patients taking therapeutic doses of diclofenac and naproxen in a multinational, doubleblind randomised trial (SUCCESS-1 in OA).

Methods A total of 13,274 patients from 1142 sites in 39 countries in Europe, South Africa, Asia, Latin America, and the United States and Canada were enrolled in the SUCCESS-1 trial. Patients were randomly assigned to fixed treatment regimens of celecoxib $200 \mathrm{mg}$ per day, celecoxib $400 \mathrm{mg}$ per day, or NSAIDs (naproxen $1000 \mathrm{mg}$ per day in the US and Canada and diclofenac $100 \mathrm{mg}$ per day in other regions).

Results Of the 13,194 patients randomised, 4421 and 4429 patients received 200 or $400 \mathrm{mg}$ per day of celecoxib respectively, 914 patients received $1000 \mathrm{mg}$ per day of naproxen, and 3510 patients received $100 \mathrm{mg}$ per day of diclofenac. Patients were mostly female (67\%), and $42 \%$ were 65 years or older (mean age: 62 years). Previous cardiovascular disease was comparable in each intent-to-treat group $(\mathrm{p}=0.25)$. ASA use was $7.9 \%$ and $8.0 \%$ at baseline, in the celecoxib and NSAID groups, respectively. The number of patients with cardiovascular and renal events adverse events is shown in the Table 1 below:

\begin{tabular}{|c|c|c|c|c|}
\hline & $\begin{array}{l}\text { Celecoxib } \\
(\mathrm{n}=\mathbf{8 8 0 0})\end{array}$ & $\begin{array}{l}\text { NSAID } \\
(n=4394)\end{array}$ & RR $(95 \% \mathrm{Cl})$ & $p$-value \\
\hline \multicolumn{5}{|l|}{ Intent-to-treat patients } \\
\hline Cardiac failure & $4(0.05 \%)$ & $9(0.2 \%)$ & $0.22(0.02,1.2)$ & 0.09 \\
\hline Oedema, peripheral & $129(1.5 \%)$ & $63(1.4 \%)$ & $1.0(0.74,1.5)$ & 0.91 \\
\hline Oedema, generalised & $42(0.5 \%)$ & $16(0.4 \%)$ & $1.3(0.67,2.9)$ & 0.47 \\
\hline Hypertension & $93(1.1 \%)$ & $54(1.2 \%)$ & $0.86(0.59,1.3)$ & 0.47 \\
\hline Hypertension, aggravated & $26(0.3 \%)$ & $13(0.3 \%)$ & $1.0(0.43,2.5)$ & 1.0 \\
\hline
\end{tabular}

Conclusion SUCCESS 1 provides additional evidence that celecoxib is associated with low incidence of cardiovascular or renal toxicity that is comparable to conventional NSAIDs.

Sponsored by Pharmacia Corporation and Pfizer Inc.

\section{SAT0095 COMPARATIVE BLOOD PRESSURE EFFECTS OF ROFECOXIB, CELECOXIB, AND PLACEBO IN PATIENTS WITH OSTEOARTHRITIS (OA): A RANDOMISED CONTROLLED TRIAL}

${ }^{1} \mathrm{GP}$ Geba, ${ }^{1} \mathrm{AB}$ Polis, ${ }^{1} \mathrm{ME}$ Dixon, ${ }^{1} \mathrm{TW}$ Dobbins, ${ }^{1} \mathrm{JE}$ Rush, ${ }^{2} \mathrm{MR}$ Weir. ${ }^{1}$ Merck and Co., Inc., West Point, PA, USA; ${ }^{2}$ University of Maryland, Baltimore, MD, USA

\subsection{6/annrheumdis-2001.470}

Background Dual inhibitors of cyclo-oxygenase (COX)- 1 and COX-2 can potentially induce elevation of systolic and diastolic blood pressure in some patients. This is thought to be due to COX-2 mediated effects on the nephron, influencing natriuresis. We examined the relative effect of selective COX-2 inhibitors, rofecoxib and celecoxib on blood pressure (BP) during a 6-week, placebo controlled OA efficacy trial.

Objectives

Methods 1082 patients with OA of the knee or hip, after withdrawal of previous therapy for OA, were randomised to treatment with rofecoxib $25 \mathrm{mg}$ (QD $(\mathrm{N}=471)$, celecoxib $200 \mathrm{mg}$ (QD $(\mathrm{N}=460)$ or placebo $(\mathrm{N}=151)$. Paracetamol was allowed as rescue during the trial. Treatment groups were similar in terms of age, race, gender, baseline OA severity, history of hypertension, and baseline BP. The mean age was 62 years, the majority were female. Greater than $40 \%$ in each group had a history of hypertension. BP (systolic, SBP and diastolic, DBP) was assessed at office visits at baseline, 2, 4, and 6 weeks in the sitting position after patients rested $10 \mathrm{~min}$. Relative OA efficacy was determined by $\%$ patients with good or excellent response to therapy (\%PGART) and WOMAC questionnaire at scheduled office visits over 6 weeks.

Results The percent of patients with pre-defined changes in SBP (increase $>20 \mathrm{~mm} \mathrm{Hg}$ and SBP $>140$ ) and DBP (increase $>15$ $\mathrm{mm} \mathrm{Hg}$ and DBP >90) was $9.6 \%$ for rofecoxib and $9.4 \%$ for celecoxib; $2.8 \%$ for rofecoxib and $2.0 \%$ for celecoxib, respectively compared to placebo $(3.3 \%$ systolic change and $2.0 \%$ diastolic change). Differences between coxibs and placebo were significant for SBP $(p=0.015)$; rofecoxib and celecoxib did not differ significantly from one another in terms of either SBP or DBP. There was one discontinuation due to hypertension (overall incidence $0.2 \%$ for rofecoxib, $0 \%$ for celecoxib, and $0 \%$ for placebo). Mean changes from baseline in SBP were $1.9 \mathrm{~mm} \mathrm{Hg}$ for rofecoxib. $0.2 \mathrm{~mm} \mathrm{Hg}$ for celecoxib, and $-4.3 \mathrm{~mm} \mathrm{Hg}$ for placebo, and in DBP were $0.3 \mathrm{~mm},-0.4 \mathrm{~mm}$, and $-2.6 \mathrm{~mm} \mathrm{Hg}$ respectively. Relief of night pain and\% PGART over six weeks were significantly greater for rofecoxib compared to celecoxib [night pain change from baseline: $-36.2 \mathrm{~mm}$ for rofecoxib vs $32.7 \mathrm{~mm}$ for celecoxib ( $\mathrm{p}=0.023$ ); PGART: $58.0 \%$ for rofecoxib vs $49.9 \%$ for celecoxib ( $p=0.014$ )]. In addition, although not a prespecified endpoint, rofecoxib resulted in significantly greater improvement than celecoxib in scores for each of the WOMAC composite domains (pain, stiffness, and physical function: $\mathrm{p}<0.01)$.

Conclusion Like dual COX-inhibiting NSAIDs, selective COX-2 inhibitors can induce elevations of systolic and diastolic blood pressure. Rofecoxib produced nearly identical small changes in 